between organisations. These relationships have continued after the project finished due to the success of the Kinship Kickabout, a project for new 'blended' families, helping them to come together through developing family team building and having fun. The project also incorporated telling stories through the medium of comics, a creative and successful way to engage and encourage children and young people to tell their personal story. We also held awareness sessions focusing on helping Kinship carers gain a better understanding of how best to support children and young people with the change and loss experienced in their lives.

In doing this project, Ardgowan hospice has increased its awareness of children and young people in Kinship care, including having changed the way that we highlight them in our clinical records and in how we capture the respective data. We have enhanced our links with statutory and other voluntary services, ensuring that children and young people in Kinship care are better able to receive integrated care at the point of need. More than that we have been able to recognise and celebrate the richness of kinship networks and the many ways in which kith and kin extend their networks to incorporate and care for bereaved children and young people.

\section{P-28 SUPPORTING TEACHERS TO HELP CHILDREN AFFECTED BY COVID-19 AND BEREAVEMENT}

${ }^{1}$ Sarah Popplestone-Helm, ${ }^{1}$ Rebecka Sparks, ${ }^{1}$ Andy Schwab, ${ }^{1}$ Pam Woodall, ${ }^{2}$ Laura Macleod. 'St Richard's Hospice, Worcester, UK; ${ }^{2}$ Worcestershire County Council, Worcester, UK

\subsection{6/spcare-2021-Hospice.49}

Background During the pandemic, the hospice social workers recognised that schools were supporting children affected by COVID-19. With intense media coverage about the virus and daily reporting of death tolls, the public were talking about death more openly. The team recognised that 'children need adults to help them understand what's going on, to help them talk about what frightens them and to help reassure them' (The Irish Childhood Bereavement Network, 2020).

Aims Supporting children and families before and following bereavement is part of the hospice social work role. During lockdown the team supported children struggling with social isolation, missing their peers, anxiety about exams, fears for their future, and concerns for loved ones. Focus on ideas to help teachers support children in school but also whilst schools were closed felt important.

Methods The team consulted with other bereavement services, and developed three virtual workshops providing guidance on supporting children through COVID-19. The aim was to encourage schools to support pupils, during and after lockdown, and help teachers recognise the need for additional support and how to refer into bereavement services. Over 250 school and nursery staff attended the online workshops.

Results Attendees reported that the training informed their practice through:

- Use of direct, compassionate language for dealing with death/ and worries about death.

- Strategies to help children remember loved ones.
- Listening and giving children time, to make them feel safe.

- Need good communication lines with parents.

The first session was recorded and added to the hospice website, information could be accessed at a later date.

Conclusions The full impact of COVID-19 on children and young people's mental health is yet to be fully understood. Work is ongoing to support schools to develop staff skills in supporting grieving children. Also, to implement bereavement policies and school bereavement champions.

\section{P-29 BEREAVEMENT, LOSS AND CHANGE DUE TO COVID-19 IN SCHOOLS, FURTHER EDUCATION COLLEGES AND YOUTH GROUPS}

${ }^{1}$ Helen Evans, ${ }^{1}$ Michelle McGannan, ${ }^{2}$ Marie Price, ${ }^{1}$ Susie Norton, ${ }^{3}$ Kate Birrell, ${ }^{4}$ Sarah Pearce, ${ }^{5}$ David Barclay. ${ }^{1}$ St. Wilfrid's Hospice, Chichester, UK; ${ }^{2}$ University of Chichester, Chichester, UK; ${ }^{3}$ West Sussex County Council, Chichester, UK; ${ }^{4}$ West Sussex CCG, Worthing, UK; ${ }^{5}$ East Sussex NHS Healthcare Trust, East Sussex, UK

\subsection{6/spcare-2021-Hospice. 50}

Background Pandemic-related issues for schools/colleges in their dealings with children/young people were apparent in the media. Pre- COVID-19 school staff attended hospice bereavement workshops but found them not specific to their needs, therefore a gap was identified. The initial approach was taken from another hospice out of area. Key issues articulated included multiple deaths/succession of deaths, psychosomatic illness in bereaved children and anxiety. Numerous pandemic-related issues may affect children (Albuquerque \& Santos, 2021), and the psychological impact has been overlooked (Rapa, Dalton, Stein, 2020). West Sussex Clinical Commissioning Group funded the initial education sessions and demand was immense. Compassionate Communities West Sussex awarded funding through a tender process to enable workshop development and extension.

Aim To provide education and support to teachers, teaching assistants and support roles through a suite of short, virtual sessions to schools, SEND settings, further education colleges and youth groups within West Sussex.

Methods This was an iterative process using a suite of virtual 1.5-hour sessions developed in collaboration with child bereavement experts and according to identified need. A move evolved to make these sessions homogeneous in population attendance and building onto a subsequent advanced follow-up session if needed. The sessions took place between November 2020 and March 2021. Online evaluations were completed by participants.

Results Staff from 154 schools, colleges and youth groups in West Sussex attended the workshops. Identified learning points included increased confidence in communicating with children impacted by loss and bereavement, accessing and utilising pertinent resources in addition to implementing strategies and techniques learnt.

Conclusion and take-home message These sessions were highly popular across West Sussex and differing themes emerged and evolved over the course of the delivery period. Only half of all schools and colleges in this county were reached during this project - funding and support to further develop this much-needed piece of work is hoped for later in 2021. 